\title{
Asstudy on influential factors of occupant window-opening behavior in an office building in China
}

Song Pan ${ }^{1}$, Yingzi Xiong ${ }^{1}$, Yiye $\mathrm{Han}^{1}$, Xingxing Zhang ${ }^{2}$,_Liang $\mathrm{Xia}^{3,{ }^{*}}$, Shen $\mathrm{Wei}^{4, *}$,

Jinshun $\mathrm{Wu}^{5}$, Mengjie $\mathrm{Han}^{2}$

${ }^{1}$ Beijing Key Laboratory of Green Built Environment and Energy Efficient Technology,

Beijing University of Technology, Beijing 100124, China

${ }^{2}$-School of Industrial Technology and Business Studies, Dalarna University, Falun 79188, Sweden

${ }^{3}$ Research Centre for Fluids and Thermal Engineering, University of Nottingham Ningbo China, Ningbo 315100, China

${ }^{4}$ The Bartlett School of Construction and Project Management, University College London (UCL), London, WC1E 7HB, UK

${ }^{5}$ College of Architecture and Civil Engineering, North China Institute of Science \&Technology, Hebei 065201, China

Corresponding authors.

E-mail addresses: shen.wei@ucl.ac.uk (S. Wei), Liang.Xia@nottingham.edu.cn (L. Xia). 


\section{Abstract}

Occupants often perform many types of behavior in buildings to adjust the indoor thermal environment. In these types, opening/closing the windows, often regarded as window-opening behavior, is more commonly observed because of its convenience. It not only improves indoor air quality to satisfy occupants' requirement for indoor thermal comfort but also influences building energy consumption. To learn more about potential factors having effects on occupants' window-opening behavior, a field study was carried out in an office building within a university in Beijing. Window state (open/closed) for a total of 5 windows in 5 offices on the second floor in 285 days $(9.5$ months) were recorded daily. Potential factors, categorized as environmental and nonenvironmental ones, were subsequently identified with their impact on windowopening behavior through logistic regression and Pearson correlation approaches. The analytical results show that occupants' window-opening behavior is more strongly correlated to environmental factors, such as indoor and outdoor air temperatures, wind speed, relative humidity, outdoor $\mathrm{PM}_{2.5}$ concentrations, solar radiation, sunshine hours, in which air temperatures dominate the influence. While the non-environmental factors, i.e. seasonal change, time of day and personal preference, also affects the patterns of window-opening probability. This paper provides solid field data on occupant window opening behavior in China, with high resolutions and demonstrates the way in analyzing and predicting the probability of window-opening behavior. Its discussion into the potential impact factors shall be useful for further investigation of the relationship 
between building energy consumption and window-opening behavior.

\section{Keywords}

window-opening behavior,_influential factors, window state, office building

\section{Introduction}

Indoor environment_regarding to both thermal condition and air quality, is important for building occupants' health and productivity. Owing to the fast development in both economy and urbanization, the demand on better indoor environment has increased. In many buildings, when people are dissatisfied with the indoor environment, they may often perform adaptive behaviors, such as opening/closing a window, adjusting clothing insulation level and changing cooling/heating setpoints, to adjust their surrounding environment [1-3]. In places with mild outdoor environment, opening windows can reduce indoor cooling demand and enhance indoor air quality simultaneously. Therefore, openable windows, have been widely selected for many buildings as a type of low-carbon solution. When the building is running in a free mode, opening windows can bring cool-and-fresh air from outdoors [4]. When the building is mechanically heated or cooled, opening windows will provide a better indoor air quality, but may increase the building's heating or cooling demand [6]. In many buildings,_openable windows are controlled manually by the occupants. Thus, a comprehensive understanding in occupants' window-opening behaviors is important to ensure a healthy indoor environment and adjust energy supply systems in buildings at a reduced consumption level [7]. 
In the past 30 years, a number of studies have been carried out to explore occupants' window-opening behavior, especially within European countries, such as the UK [716], Switzerland [17-19], Denmark [1,20], Germany [21-22] and Italy [23]. Nevertheless, this is very limited contribution_[24]_from China by providing solid evidence_on how people in China context operate their windows. A thorough review work on occupants' window-opening behavior studies is conducted as following Sections 1.1 and 1.2, which focus on influential factors of occupants' window-opening behavior.

\subsection{Existing studies in the Europe}

In Switzerland,_Haldi and Robinson [2,17-19] carried out a detailed analysis of the influences from occupancy patterns, indoor air temperature and outdoor climate parameters (i.e. temperature, wind speed and direction, relative humidity and rainfall) on window-opening behavior in their experimental building, based on data collected over 7 years. From the analysis, they reported that indoor air temperature was a dominating factor influencing window-opening behavior because indoor air temperature has a direct link to occupants' decision of window operation. Yun et al. [14] conducted a field monitoring_study in 4 offices and demonstrated close links between impact factors $\left(\mathrm{CO}_{2}\right.$ concentrations, prevailing internal and external temperature, occupancy schedules and window control patterns. From the study, they also revealed that there were statistically significant relationships between occupants' window uses and indoor environmental parameters, i.e. indoor thermal stimuli and $\mathrm{CO}_{2}$ 
concentrations, and also the previous window state, i.e. whether it has been opened or closed, was a crucial factor in the relationship. Occupancy has been suggested as another important driver of window-opening behaviors, which has been classified as time of arrival, time of departure and time of day. In another study, Yun [25] further justified the strong link between window-opening behavior and time of day. He proposed that occupants attempted to restore their comfort in the easiest way possible, which, of course, were influenced by many contextual factors. Contextual drivers have been defined as those factors that have an indirect influence on window-opening behavior, and they were including many factors such as window orientation, window type, seasonal change, time of day and occupancy pattern. Additionally, it has been observed that there was an apparent difference in window positions during the night time among individual occupants, in both summer and winter times. Some windows were rigorously closed at the end of almost every day, whilst others were left open across a very large range of temperature conditions. Andersen et al. [26] did repeated surveys on occupant control of the indoor environment in Danish dwellings, and analyzed influences from a number of factors, i.e. outdoor air temperature, indoor air quality, thermal sensation, noise level, outdoor solar radiation, wind speed, sunshine hours, age, gender, house property ownership and type of heating systems. From the study, they concluded that the window-opening behavior was strongly correlated to outdoor air temperature and occupants' perception of the environment and factors concerning the dwelling also affected the window-opening behavior. Wei et al. [27] 
suggested that even if all common factors were the same, occupants may still perform different window operations in office buildings, and this difference could_be explained by personal preference. And based on the frequency of opening windows, they classified survey objects into three categories: habitual closers, adjusters and leave openers. In studies carried out by Rijal et al. [12], Haldi and Robinson [19]_and Yun et al. [28], window users have been termed as 'active', 'medium' and 'passive'. These results also reflect the various behavior for different users, which were caused by occupants personal preference. The potential factors that influence window-opening behavior are summarized from above studies, as shown in Table 1.

Table 1. The influential_factors of occupants' window-opening behavior

\begin{tabular}{l|lll}
\hline Environmental factors & \multicolumn{3}{|c}{ Non-environmental factors } \\
\hline Outdoor environment & Age & Time of day & Previous status of the window \\
(dominated by outdoor air & Gender & Heating modes & House Property ownership \\
temperature and relative & Season & Window type & Window orientation \\
humidity) & & & \\
\hline Indoor environment & Smoking & Building type & Occupancy pattern \\
(dominated by indoor air & Presence & Room type & Personal preference \\
temperature and air quality) & Floor level & & \\
\hline
\end{tabular}

\section{2_Existing studies in China}

In China, Li et_al. [24] carried out a 2-month field observation on occupant windowopening behavior in a naturalty ventilated office building during the transition seasons. 
From the study, they found that outdoor air temperature significantly affected windowopening behavior among other factors such as outdoor relative humidity, indoor air temperature, indoor relative humidity, and indoor $\mathrm{CO}_{2}$ concentrations, which have much less effect. The main trigger point for opening windows in transition seasons, revealed by them, is from occupants' desire to improve the indoor thermal and air quality environment. Weihuang Chen [29] analysed the influence of thermal comfort due to window-opening behavior in hot summer and cold winter zone, in 2009. Jian Zhang [30] analysed the influence of building orientation and height on windowopening behavior in 2011.

Comparing to the related foreign research, there is a lack of in-depth research into occupants' window-opening behavior, especially aiming in China scenario since China has a very different background and condition from western countries in terms of its air pollution and speed of economic development. As a result, to handle this particularity, a real-time monitoring for a long period was carried out in this paper, aiming at finding out and quantifying the influence of environmental/non-environment factors on window-opening behavior in China context. Beyond that, this study developed a dedicated analytical model for window-opening behavior that can be applied further in energy consumption simulation in China context.

This paper aims to provide high-quality data resolution to the research of windowopening behavior in China, through development of statistic analytical models. This work is expected to fill in the research gap existing in occupant window-opening 
behavior of office buildings. In this paper, occupants' window-opening behavior and relevant influential factors were monitored in an office building in a University in Beijing with high resolutions (including window state, indoor and outdoor air temperatures, outdoor relative humidity, outdoor $\mathrm{PM}_{2.5}$ concentrations, outdoor wind speed and direction, solar radiation, sunshine hours, seasonal change, time of day, personal preference). An integrated model, combined with logistic regression and Pearson correlation approaches, was then developed to analyze the recorded data. The potential influential factors on occupants' window-opening behavior were finally identified in the case study building, which shall be meaningful for the future integrated behavioral modeling in a whole building or cluster scale.

\section{Method of study}

\subsection{Building description}

The case office building was constructed of reinforced concrete and brick, which located at a university in Beijing. The building shape and office layout were very common for office buildings in China. Around the building, there were no tall buildings and trees blocking solar gains and external noise was ignorable. As shown in Fig. 1 (a), the building has two stories, where laboratories were based on the ground floor, and a total of 9 offices with same size of $10 \mathrm{~m}^{2}$ were placed on the second floor. The typical internal layout of all offices is shown in Fig. 1 (b). The geometry information of the measured offices is shown in Table 2. In these 9 offices, 5 offices were applicable and selected for the experiment. 
Each office can accommodate two occupants, with a south-facing sliding window. During the experiment, there was only one occupant in each office. In winter, radiator and natural gas boiler were used as main heating generator, with municipal hot water heating as auxiliary heating occasionally. In summer, split-type air conditioners were used to supply cooling. During transition seasons (the period from $1^{\text {st }}$ October to $15^{\text {th }}$ November and $15^{\text {th }}$ March to $16^{\text {th }}$ May), natural ventilation was the main strategy. To investigate the effect of regional noise on window-opening behavior, questionnaires were developed, delivered and answered. Based on the answers, the regional noise seems no significant influence on window-opening behavior in this case. The occupants of all 5 offices were all non-smoking, consisting of two males and three females, who had lived in Beijing for many years and adapted well to the local climate.

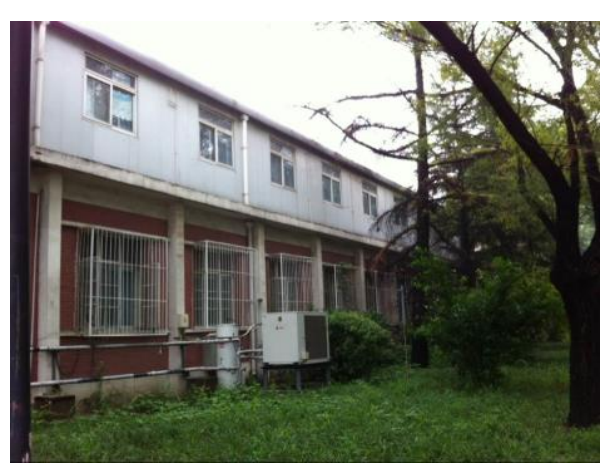

(a)

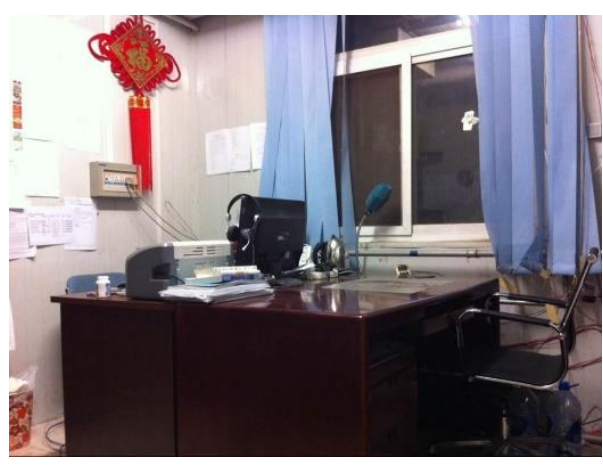

(b)

Fig. 1 The case study building (a) and a typical office (b)

Table 2. Basic information of measured offices

\begin{tabular}{l|c|c|c|c|c}
\hline the room & size $/ \mathrm{m}^{2}$ & the orientation of & window & the number of & gate \\
& & windows_ & form & windows & number \\
\hline
\end{tabular}




\begin{tabular}{l|l|l|l|l|l}
\hline 202 & 11.16 & & & \\
\hline 203 & 10.23 & & & \\
\hline 205 & 10.23 & south & Push-pull & 1 & 1 \\
\hline 206 & 10.23 & & type & & \\
\hline 208 & 10.23 & & & & \\
\hline
\end{tabular}

\subsection{Measured factors}

This study covered 2_transition seasons, i.e. from $1^{\text {st }}$ October to_ $15^{\text {th }}$ November, 2014 and from $15^{\text {th }}$ March to $16^{\text {th }}$ May, 2015, 1 heating season, i.e. from $15^{\text {th }}$ November, 2014 to $15^{\text {th }}$ March, 2015 and 1 cooling season, i.e. $16^{\text {th }}{ }_{-}$May to $15^{\text {th }}$ July, 2015. During transition seasons, occupants mainly adjusted indoor air quality using natural ventilation. During heating season, circulating water radiators were used for the indoor air temperature and split type air conditioners were designed for the indoor air temperature during cooling season. In cooling season, occupants could adjust the setting value via control panel installed on the interior wall but this was not flexible in heating season as the heating was controlled by central plant. During the monitoring, infrared instruments (recording interval: $1 \mathrm{~min}$; induction range: $5 \mathrm{~m}$ ) were used to record occupancy of the monitored offices; window displacement testers were applied to detect and record the state of office windows (recording interval: $10 \mathrm{~min}$; induction distance: $3 \mathrm{~cm}$ ); indoor air temperature sensors (recording interval: $10 \mathrm{~min}$; precision: $\pm 0.5^{\circ} \mathrm{C}$ ) were installed to used to measure and record indoor air temperature. All the above measuring devices have been shown in Fig. 2 (a-c). A portable outdoor 
meteorological sensor (recording interval: $1 \mathrm{~min}$ ) was installed at the top of the office building, as shown in Fig. 2 (d).

In the experiment, $\mathrm{PM}_{2.5}$ measurement was also considered. It refers to the atmospheric fine particulate matter_with a diameter less than $2.5 \mu \mathrm{m}$, which has proven with a direct and harmful effect on health, especially for the respiratory system. The increase in $\mathrm{PM}_{2.5}$ _concentrations is positively correlated with the death rate_from_respiratory diseases_[31], and such truth influence a lot on occupant's decision whether open windows or not. By considering the indirect influence_of high $\mathrm{PM}_{2.5}$ concentrations on window-opening behavior, a questionnaire survey was completed before the experiment_about whether people would close windows when outdoor $\mathrm{PM}_{2.5}$ concentrations was high. The survey_result showed that people tended to close windows for better indoor air quality so as to keep healthy when it comes to high outdoor $\mathrm{PM}_{2.5}$ concentrations. In consideration of serious air pollution in Beijing in recent years and the inter-linked_influence of outdoor $\mathrm{PM}_{2.5}$ concentrations on window-opening behavior, the outdoor $\mathrm{PM}_{2.5}$ concentrations were also recorded based on the data measured in the Temple of Heaven which had a linear distance of $5 \mathrm{~km}$ from the investigated building. In summary, the recorded data of this study included (I) environmental factors: indoor and outdoor air temperature $\left({ }^{\circ} \mathrm{C}\right)$,_outdoor relative humidity $(\%)$,_outdoor wind direction $\left(^{\circ}\right)$, outdoor wind speed $(\mathrm{m} / \mathrm{s})$,_solar radiation $\left(\mathrm{W} / \mathrm{m}^{2}\right)$,_outdoor $\mathrm{PM}_{2.5}$ concentrations $\left(\mathrm{ug} / \mathrm{m}^{3}\right)$,_sunshine hours ( the hour of daily radiation level is higher than $120 \mathrm{~W} / \mathrm{m}^{2}$ ), and (II) non-environmental factors:_seasonal change, time of day, and_personal 
preference

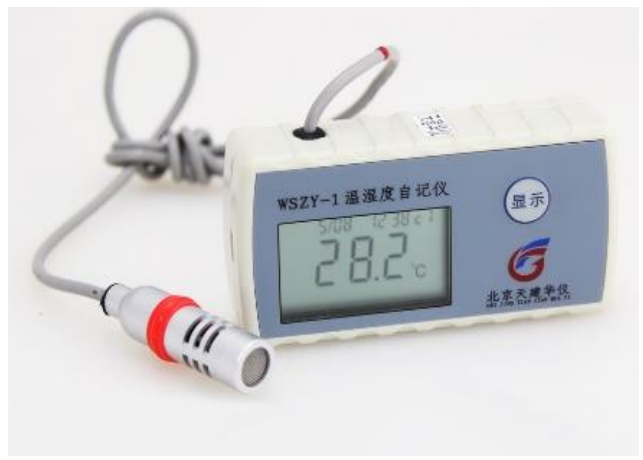

(a)

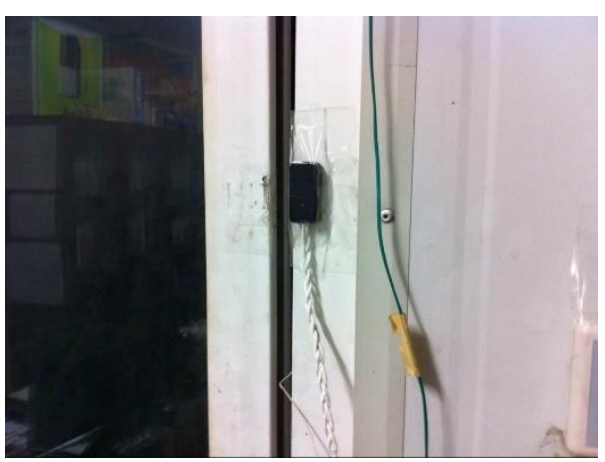

(c)

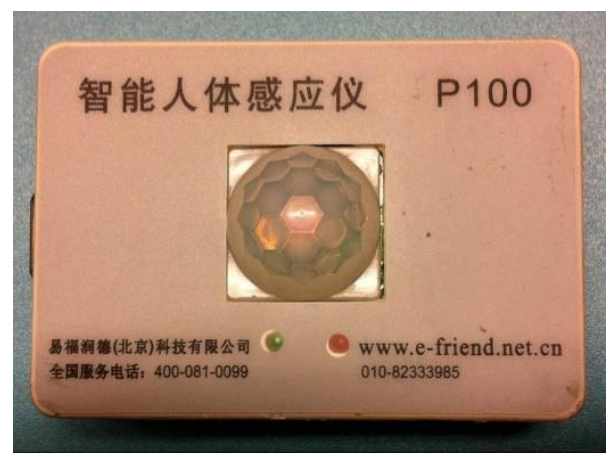

(b)

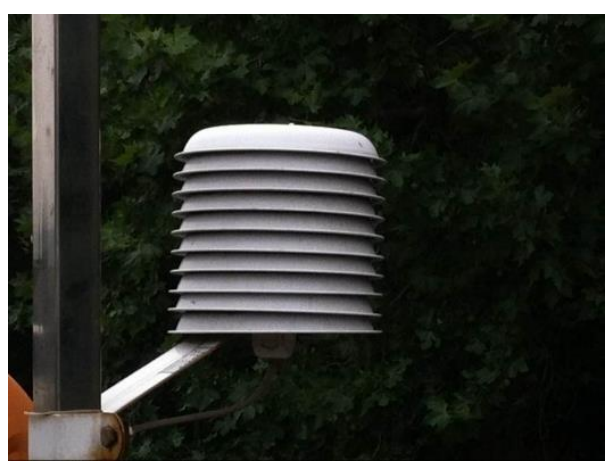

(d)

Fig. 2 Indoor temperature measuring device (a); Intelligent human body inductor (b); The window displacement tester (c) and Outdoor temperature measuring device (d)

\subsection{Measuring devices}

To avoid the impact of radiators/convectors on temperature measurement, an indoor air temperature sensor TR (v1.2) produced by the China Architecture Science Institute was placed on a platform of 1.8 meters from the floor, staying a distance of at least $1 \mathrm{~m}$ from the nearest radiator/convection inverter. By doing so, the temperature was considered the same as the one at occupant height after tests over several days before measurement. All sensors had been calibrated by the manufacturer before the measurement, an additional calibration was carried out every two months during the monitoring period. 
The portable outdoor meteorological weather station was placed on the roof at $1-\mathrm{m}$ height over the roof to ensure no influence from the heated generated from the building itself. An infrared instrument P-100 (v1.0) was installed on the inside walls of the office at a 2-m height and close to the office chair. Its role was to detect infrared wavelengths emitted by the human body, with a radius of approximately $5 \mathrm{~m}$. The location of the infrared instrument P-100 was chosen to avoid any impact on its measurement results from devices such as computers, water fountains and radiators.

The state of the window (open/closed) was measured by a window displacement tester D-100 which automatically recorded the window state dynamically. The window displacement tester recorded the window state by means of the magnetic induction of two dry spring pipes positioned on the window. When the magnet force is approached, the dry reed pipes are connected; while magnet is weakening, the dry reed pipes are separated. So the opening state_of the window are detected. The shortest time of induction switch is not less than 3 seconds, and the highest_distance where measuring devices can be induced by the magnet is $3 \mathrm{~cm}$.

\section{Data processing and results analysis}

\subsection{Environmental factors}

The outdoor and indoor air temperatures have proven as the dominating influential factors on window-opening behavior in many studies [2,6,17-19,24,29]. In this section, the analysis is in turn to assess the impact from both outdoor and indoor air temperatures in this case building. Meanwhile, due to heavy air pollution caused by high $\mathrm{PM}_{2.5}$ 
concentrations in China, the influence of outdoor $\mathrm{PM}_{2.5}$ concentrations on windowopening behavior has also been investigated.

A logistic regression approach has been used to analyze the original data by addressing the probability of the window switch against the outdoor/indoor air temperature and $\mathrm{PM}_{2.5}$ concentrations. Logistic regression analysis [32] is a statistic method that defines the probability of specific event happening (e.g. opening a window) based on relevant influential factors (e.g. outdoor/indoor air temperature or $\mathrm{PM}_{2.5}$ concentrations). When using logistic regression, a useful method to identify the contribution of individual factors to the event happening is called Wald statistic test, which has a chi-square distribution. Thus, a significant 2 tailed P-value of a particular predictor reflects that this predictor plays an important role in the logistic regression model. The relation is given_in Eq. (1):

$$
P=\exp (a+b x) /[1+\exp (a+b x)]
$$

where, $P \_$refers to window-opening probability, and $x$ is relevant influential factors, $a \_$and_b_are_constants, which represent the intercept and regression coefficients, respectively.

\subsubsection{Outdoor air temperature}

Fig. 3 displays shows the variation of window-opening probability with increase in outdoor air temperature. It is observed that the window-opening probability increases with the increase of outdoor air temperature. The result was similar to those obtained from the European studies $[12,15,19,33]$. In addition, when outdoor air temperature was 
lower than $10^{\circ} \mathrm{C}$, indoor occupants generally kept their windows closed, and when outdoor air temperature was higher than $10^{\circ} \mathrm{C}$, it started to influence greatly on windowopening probability. For instance, when the outdoor air temperature reached its highest level of $35.2^{\circ} \mathrm{C}$, the maximum window-opening prbability was reached, which was 65.4\%. In Fig. 3, the intercept $a=-1.45 \pm 0.04$ and the regression $b=0.045 \pm$ 0.002 in Eq. (1) by using the logistic regression analysis.

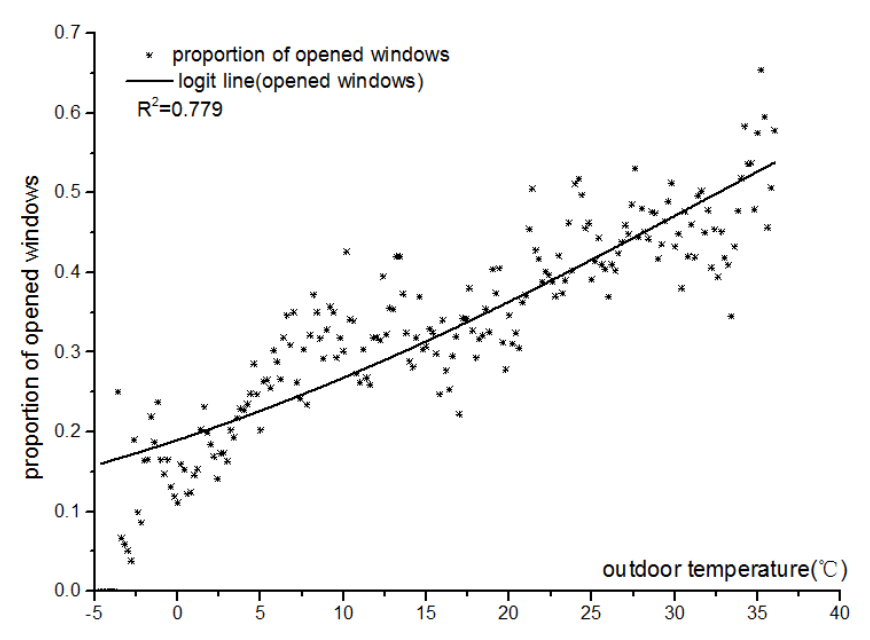

Fig. 3 Relationship between window-opening probability and outdoor air temperature

\subsubsection{Indoor air temperature}

Fig. 4 illustrates the window-opening probability varying with increase in indoor air temperature. The window-opening probability seems to increase with the higher indoor air temperature, which is also in consistent with the results gained by past researchers [12,33-34]. When the indoor air temperature was lower than $22^{\circ} \mathrm{C}$, indoor occupants generally kept their windows closed, and when indoor temperature was higher than $27^{\circ} \mathrm{C}$, the indoor air temperature turned to affect significantly on window-opening probability. The maximum probability of window-opening achieved at $62.9 \%$ when the 
intdoor air temperature rose to its highest level of $29.6^{\circ} \mathrm{C}$. By using the logistic regression for the data in Fig. 4, the intercept: $a=-4.70 \pm 0.23$, and the regression: $b=0.171 \pm 0.009$ in Eq. (1).

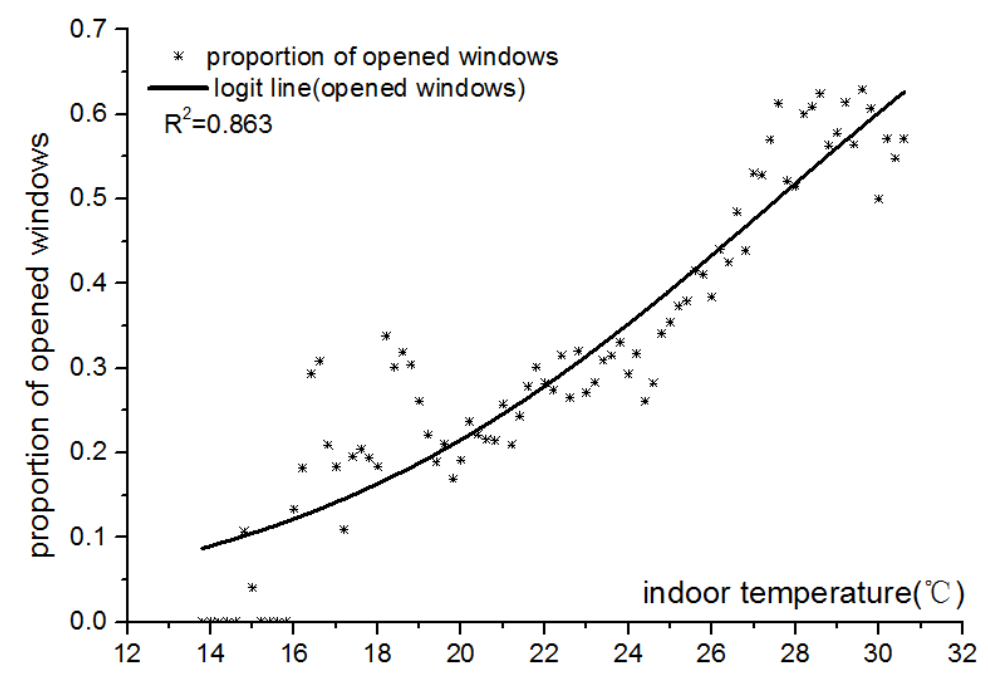

Fig. 4 Relationship between window-opening probability and indoor air temperature

\subsubsection{Outdoor PM2.5 concentrations}

Beijing has seriously suffered from outdoor air pollution because of high $\mathrm{PM}_{2.5}$ concentrations in recent years, especially in winter and transition seasons. Hence, the indirect impact of outdoor $\mathrm{PM}_{2.5}$ concentrations on window-opening behavior was also investigated when considering the outdoor air temperature in parallel since it dominates the influence on window state $[9,12,19,22]$. The analysis, therefore, was a 3-dimension problem (probability against $\mathrm{PM}_{2.5}$ concentrations and outdoor air temperature) rather than a 2-dimension issue. The logistic regression analysis was applied again to identify whether outdoor $\mathrm{PM}_{2.5}$ had a significant impact on window state in the case building. Both outdoor air temperature and $\mathrm{PM}_{2.5}$ concentrations were set up as predictors of the 
model and the observed state of windows was regarded as the model output. The ultimate regression results gave that both predictors have a P-value of 0.000 , meaning that both the two predictors had a significant influence on the observed window state.

\subsubsection{Correlation analysis for all factors}

Correlation approach has been widely applied in the analysis of the correlation between occupants' window-opening behavior and its influential factors. This method is adopted to analyze the influence of environmental factors on window-opening behavior in this study.

In statistics, correlation analysis refers to the analysis on two or more relevant variables. A significant feature of correlation analysis is that all variables are given the_same priority in the analysis. In this paper, the Pearson correlation coefficient, $r$, has been introduced to calculate the data of the interval variable, as presented in Eq. (2).

$$
r=\sum_{i=1}^{n}\left(x_{i}-x\right)\left(y_{i}-y\right) / \sum_{i=1}^{n}\left(x_{i}-x\right)^{2} \sum_{i=1}^{n}\left(y_{i}-y\right)^{2}
$$

where, $\mathrm{r}$ is the correlation coefficient; $\mathrm{x}$ and $\mathrm{y}$ are the mean value of $\mathrm{x}$ and $\mathrm{y}$ respectively;

$x_{i}$ and $y_{i}$ are the ith observed variable for_x and $\mathrm{y}$ respectively.

Because of existing sampling errors, the correlation coefficient between two variables not being ' 0 ' does not mean that the correlation coefficient between them in all samples not being ' 0 '. As a result, a test needs to be performed to examine the result of the correlation coefficient. The null hypothesis of the examination is that the correlation coefficient between two variables in all samples is ' 0 '. The tool of Statistical Product and Service Solutions (SPSS) is hereby applied used in calculating the probability of 
the hypothesis correctness, as defined in Eq. (3).

$$
t=r \cdot(n-2) /\left(1-r^{2}\right)
$$

Where, $n$ is the number of sample observations; $n-2$ is degrees of freedom.

When the significance probability, i.e., $t$, for the correlation coefficient is less than 0.05 , it is indicates that the correlation between the two variables is significant; when it's less than 0.01 , the correlation between two variables becomes much more significant; when it is higher than 0.05 , there is no significant correlation between the two variables, and $t$ is only the probability value.

The results from the correlation analysis are listed_in Table 3, illustrating that except wind direction $(t=0.075)$, the significance probabilities of indoor air temperature, outdoor air temperature, wind speed, relative humidity and outdoor $\mathrm{PM}_{2.5}$ concentrations, solar radiation, and sunshine hours were all less than 0.05 . This means that these factors have statistical significance and they can be used to illustrate the relevance of parameter and the window-opening probability.

The correlation coefficient of outdoor air temperature parameters was 0.507 , indicating its relatively strong correlation with the window-opening probability (correlation coefficient greater than or equal to 0.5 representing relatively strong correlation). The results of correlation analysis demonstrated that the probability of window being opened would be increasing with the higher outdoor air temperature, consistent with existing previous studies [12,15,19,33]. The correlation coefficient of indoor air temperature parameters was 0.2 , reflecting the weaker correlation comparing to outdoor 
air temperature parameters. Except the wind direction, the correlation coefficients of other factors had statistical significance but much weaker comparing to outdoor and indoor air temperatures. Factors, i.e. outdoor relative humidity, wind speed, outdoor $\mathrm{PM}_{2.5}$ concentrations and the sunshine hours had a rather negative correlation with window-opening probability, indicating the values of window being closed was inversely proportional to these parameters. It can be interpreted that being exposed to high humidity, high speed, high $\mathrm{PM}_{2.5}$ concentrations, or long sunshine hours may cause discomfort to the indoor occupants.

Table 3. Correlation_between the probability of window being_opened and environmental factors

\begin{tabular}{|c|c|c|c|c|c|}
\hline \multirow[b]{2}{*}{ Environmental conditions } & \multicolumn{2}{|c|}{$\begin{array}{l}\text { Descriptive } \\
\text { statistics }\end{array}$} & \multicolumn{3}{|c|}{$\begin{array}{l}\text { Correlation between environmental } \\
\text { parameters and window opening probability }\end{array}$} \\
\hline & $\begin{array}{l}\text { mean } \\
\text { value }\end{array}$ & $\begin{array}{c}\text { standard } \\
\text { deviatio } \\
\mathrm{n}\end{array}$ & $\begin{array}{l}\text { correlation } \\
\text { coefficient }\end{array}$ & $\begin{array}{l}\text { significance } \\
\text { probability }\end{array}$ & covariance \\
\hline Indoor temperature $\left({ }^{\circ} \mathrm{C}\right)$ & 23.35 & 2.841 & $0.200^{* *}$ & 0.000 & 0.268 \\
\hline Outdoor temperature $\left({ }^{\circ} \mathrm{C}\right)$ & 15.65 & 10.734 & $0.507^{* *}$ & 0.000 & 1.044 \\
\hline Wind speed (m/s) & 0.67 & 0.782 & $-0.024 * *$ & 0.000 & -0.009 \\
\hline Wind direction $\left(^{\circ}\right)$ & 189.51 & 99.703 & $0.009 * *$ & 0.075 & 0.425 \\
\hline $\begin{array}{l}\text { Outdoor relative humidity } \\
\qquad(\%)\end{array}$ & 45.91 & 20.626 & $-0.012 *$ & 0.019 & -0.116 \\
\hline $\begin{array}{c}\text { Outdoor } \mathrm{PM}_{2.5} \\
\text { concentrations }\left(\mathrm{ug} / \mathrm{m}^{3}\right)\end{array}$ & 91.58 & 98.708 & $-0.056 * *$ & 0.000 & -2.517 \\
\hline Solar radiation $\left(\mathrm{W} / \mathrm{m}^{2}\right)$ & 265.05 & 291.955 & $0.063^{* *}$ & 0.000 & 8.609 \\
\hline Sunshine time (h) & 12.41 & 6.012 & $-0.082 * *$ & 0.000 & -0.233 \\
\hline
\end{tabular}

** significantly correlated on 0.01 level (bilateral);* significantly correlated on 0.05 level (bilateral)

\subsection{Non-environmental factors}

This section presented the detailed analysis of the impacts of non-environmental factors to occupants' window opening behaviors, including_seasonal change, time of day and 
personal preference.

\subsubsection{Seasonal change}

Fig. 5 illustrates the window-opening probability varying with time, the parameters including outdoor air temperature, indoor air temperature. It can be seen that the variation profile of window-opening probability was similar to that of the outdoor air temperature, but not similar to that of the indoor air temperature. In winter, when the outdoor air temperature was lowest, the window-opening probability reached the minimum nearly at the same time, reflecting an action of closing windows to prevent cold air flow going into the room. During this period, however, the indoor air temperature was almost keeping unchanged. In summer, the window-opening probability and the outdoor air temperature almost achieved their maximum values simultaneously, demonstrating the strong impact of outdoor air temperature on the operation of windows. In addition, the variation of year-round outdoor air temperature exhibited a cosine law, which presented a strong correlation with window-opening probability. Such characterized variation along with the outdoor air temperature is meaningful for the occupant behavior modelling_buildings. 


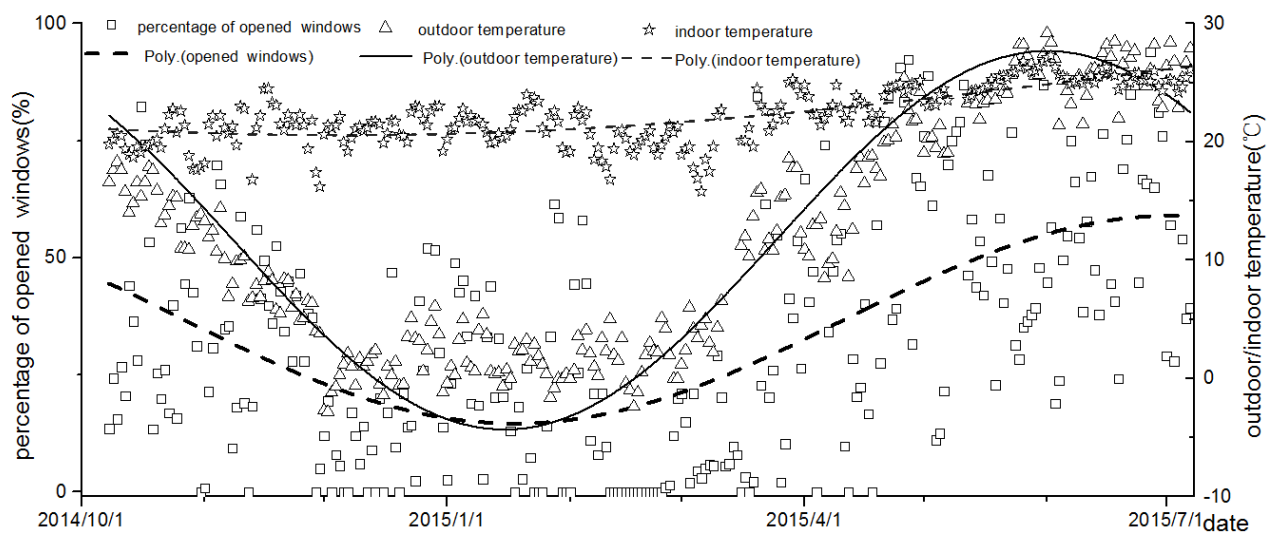

Fig. 5 Relationship between window-opening probability and indoor and outdoor air

temperature over time

Fig. 6 gives the changes in the relationship between window-opening probability and indoor air temperature during the heating season, transition seasons and cooling season. As indoor air temperature raised, the window-opening probability became higher. When the temperature was in the range of $21^{\circ} \mathrm{C}$ to $27^{\circ} \mathrm{C}$, there were different windowopening probabilities for those three seasons at the same temperature range. Besides, window were most likely to be kept opened during transition seasons. One possible reason was that natural ventilation was the only way to improve indoor thermal comfort and indoor air quality during transition seasons. In addition, there was a more comfortable outdoor air temperature when the indoor air temperature was in the range of $21^{\circ} \mathrm{C}$ to $27^{\circ} \mathrm{C}$, even lower or higher during transition seasons. In that case, indoor occupants would prefer more natural ventilation to improve the indoor air environment. On the other hand, comparing to cooling season, window-opening probabilities for heating season were much higher at the same indoor air temperature range. One 
possible explanation is that the indoor heating system was operated centrally during the heating season, leading to a higher percentage of uncomfortable indoor temperature, and opening the windows were considered the only ways to enhance the indoor thermal comfort.

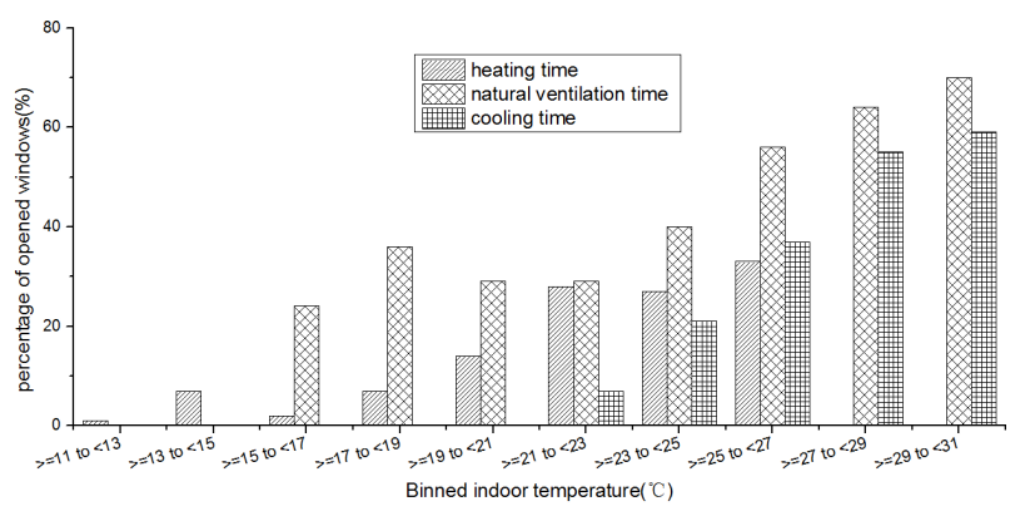

Fig. 6 Relationship between window-opening probability and indoor air temperature in

\section{different seasons}

In Fig. 7, the detailed changes in the relationship between window-opening probability and outdoor air temperature are illustrated during heating season, transition seasons and cooling season. The window-opening probability changed proportionally to the outdoor air temperature. There were different window-opening probabilities for those three seasons even at the same temperature range. In comparison to cooling season, the probability of window being opened was higher during transition seasons for the same outdoor air temperature range of $17^{\circ} \mathrm{C}$ to $35^{\circ} \mathrm{C}$. This is probably because only the natural ventilation was adopted to improve indoor thermal comfort and indoor air quality during transition seasons. The probability of window being opened was lower during transition seasons than that in the heating season for the same outdoor air 
temperature range of $2^{\circ} \mathrm{C}$ to $17^{\circ} \mathrm{C}$. It is mainly the same reason as the case result in Fig. 6, where central heating brought forward too much uncomfortable, resulting in more frequent switch of window status. In addition, it also reflects that window-opening behavior is the result of all kinds of all_comprehensive factors.

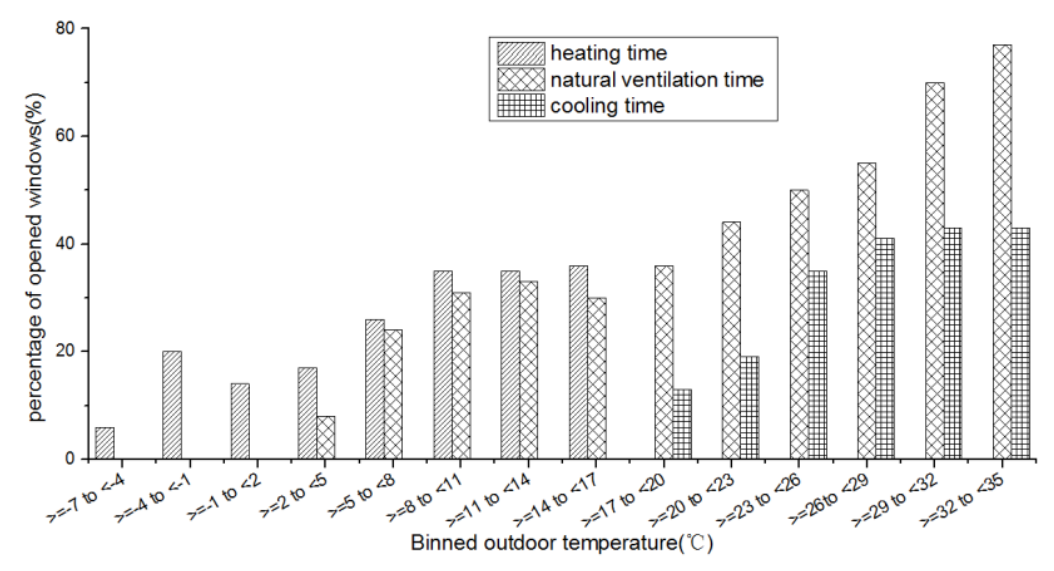

Fig. 7 Relationship between window-opening probability and outdoor air temperature in

$$
\text { different seasons }
$$

\subsubsection{Time of day}

Previous studies have shown that the change of window states often occurred at the time when occupants arrived or left their offices [14-15,19,22]. This is usually reflected by the factor called time of day. Fig. 8 shows the proportion of change of the window state from opened to closed (a) and from closed to opened (b). It can be seen that indoor occupants tended to open their windows when they firstly arrived at their offices and closed their windows when they left their offices at the end of the day. Fig. 8 (b) reveals an interesting finding that during cooling season, people preferred to open the windows to inlet fresh air in the early morning, although there would be strong direct sunlight for south-facing windows in the late morning. This finding proves that people in this 
case prefer to open windows to increase the air flow for higher indoor air quality.

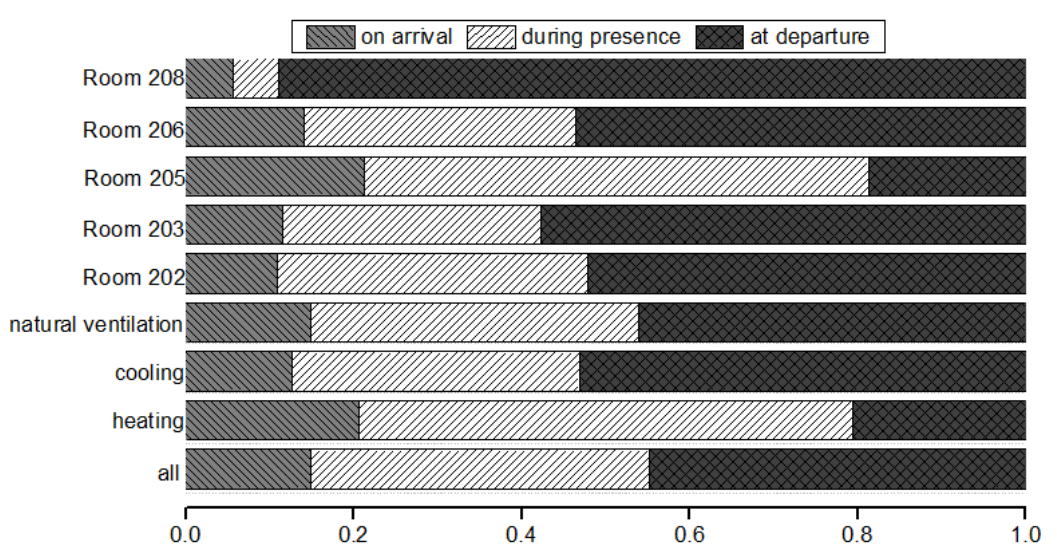

(a)

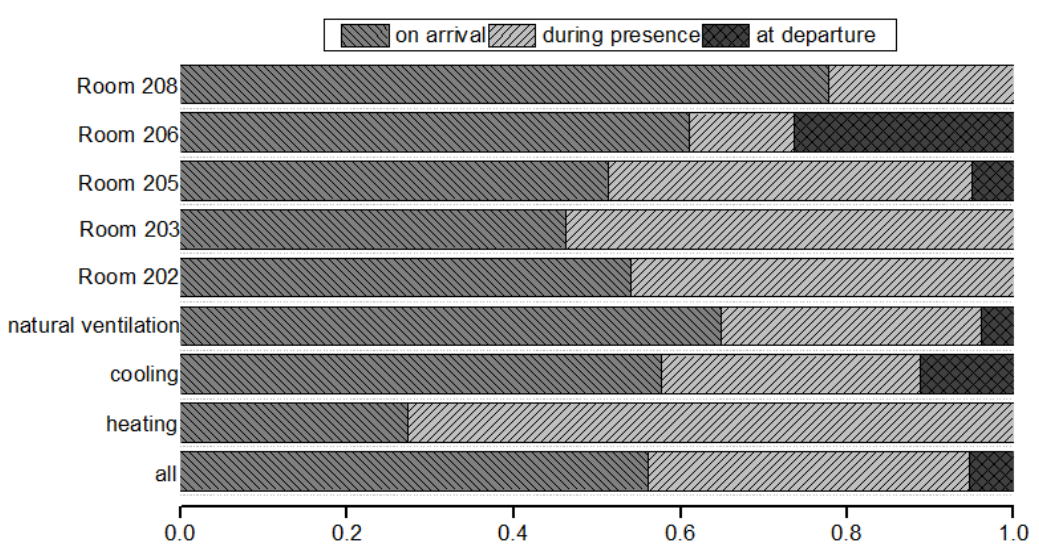

(b)

Fig. 8 Relationship between time of day and window closure (a) and Open (b)

It is well-known that when occupants come to their offices in one day, their windows may have be already opened or closed. When they feel uncomfortable, they will change the window state to adjust the indoor environment. As shown in Fig. 9 (a), when occupants arrived at their offices with closed windows, the window state would not change until they felt uncomfortable. Then, the window state would been kept at that state until occupants felt uncomfortable. In most case, people often close windows 
when they leave their offices at the end of day. However, occupants in this case preferred to_keeping window open until next arrival in order to improve indoor air quality through natural ventilation. In addition, the other situation is shown in Fig.9 (b).

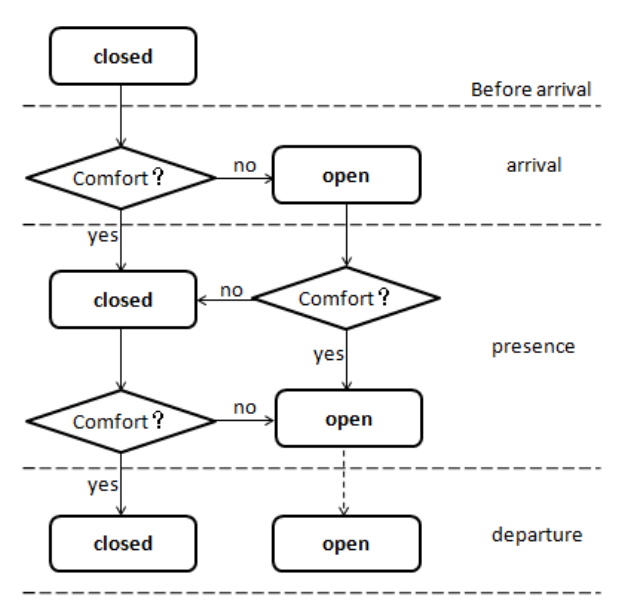

(a)

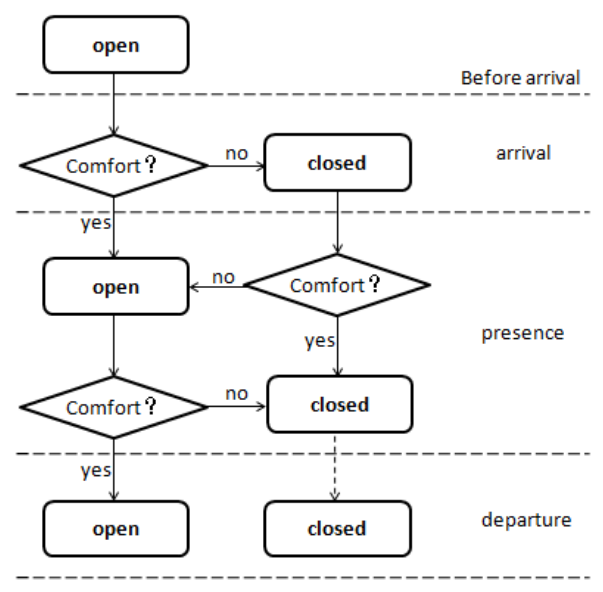

(b)

Fig. 9 The change of window status in different time periods when it's closed (a) and Open (b)

\section{before arrival}

The variation of the window-opening probability in the 24 hours of each season in all offices is depicted in Fig. 10. The window-opening probability first increased and then decreased in the day for all seasons. In addition, it can be seen that the window-opening probability climbed to the highest values in core working time till the late afternoon. One possible reason is that the solar illumination is strongest for the windows facing south at noon, and the indoor temperature is higher than morning or afternoon, when an improvement for indoor environment is needed. 


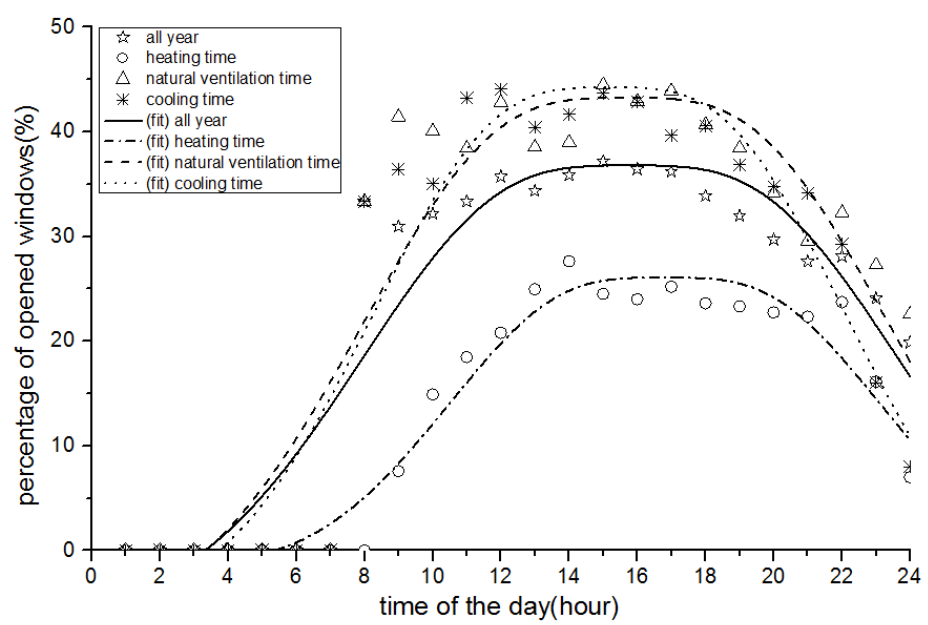

Fig. 10 The change of window-opening probability in different time periods

\subsubsection{Personal preference}

Table 4 lists some basic information of occupant behavior differences for all monitored offices. The percentage of window-opening state has been used to distinguish the differences in occupant behavior. From Table 4, it can be seen that the window-opening rates for all five offices were between $15.0 \%$ and 48.7\%, and Rooms 202, 206 and 208 had more time with open windows. On the other hand, the average times for each occupant to open their window in a week has been used to judge the frequency of occupant behavior. The difference in average time for each occupant can also reflect the contribution of personal preference. It was defined a low frequency as the times from 0 to 2.4, an average frequency when the times from 2.4 to 5.6, and a high frequency when the time more than 5.6. The result in the last column of Table 4 illustrates that Room 205, 206 have the most frequent occupant behavior.

Table 4: The_window probability description for each room 


\begin{tabular}{ccccccccc}
\hline Ref. & Nb.Pers & Age & Gender & $\begin{array}{c}\text { Ratio } \\
\text { open }\end{array}$ & Actions & Smoking & Predictive & $\begin{array}{c}\text { Overall } \\
\text { activity }\end{array}$ \\
\hline 202 & 1 & 42 & Male & $48.7 \%$ & 4.68 & No & No & Average \\
203 & 1 & 39 & Female & $22.0 \%$ & 2.54 & No & No & Average \\
205 & 1 & 43 & Male & $15.0 \%$ & 7.80 & No & No & High \\
206 & 1 & 50 & Female & $43.4 \%$ & 6.98 & No & No & High \\
208 & 1 & 45 & Female & $31.2 \%$ & 1.76 & No & Yes & Low \\
\hline
\end{tabular}

Actions: the percentage of the open window per person per week

It is worth noting that the trend of occupant behavior is defined as a predictable case if the window-opening probability rises with the increase of indoor and outdoor temperatures. Fig. 11 predicts the window-opening probability against different occupants when indoor or outdoor air temperature rises. The behavior of occupant in Room 208 has been considered be predictable. Nevertheless, in regard to a certain occupant, the trend of occupant behavior referring to indoor air temperature or outdoor air temerature was_not all consistent with the general trend.

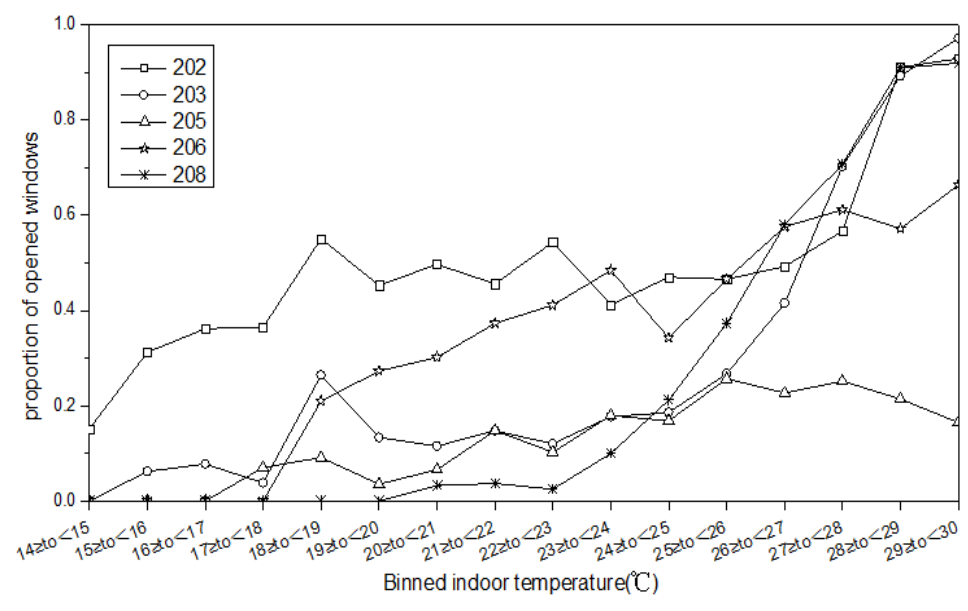

(a) 


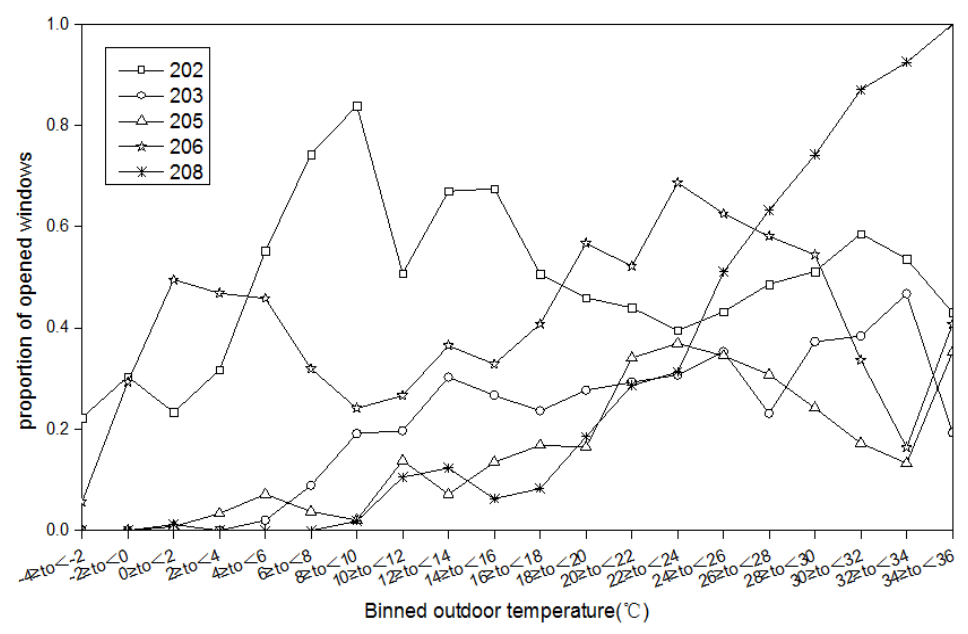

(b)

Fig. 11 Rrelationship between personal preference and indoor temperature (a) and Outdoor

temperature (b)

\section{Conclusions and discussion}

This paper elaborates a longitudinal field measurement on occupant window-opening behavior and their relevant influential factors for a period of 9.5 months in an office building in Beijing. The results show that all these factors, i.e. indoor and outdoor air temperatures, seasonal change, personal preference, time of day all have performed great influences on window-opening behavior. Main conclusions are as follows:

1) Environmental factors that affect window-opening behavior are mainly indoor and outdoor air temperatures, against other factors. With the increase of indoor and outdoor air temperatures, the window-opening probability will gradually rises and the trend is in line with the logit model with a good goodness-of-fit : the goodness-of-fit for outdoor temperature is 0.779 , and it is 0.863 for indoor air temperature.

2) In addition to indoor and outdoor air temperatures, other factors, such as wind speed, 
relative humidity, outdoor $\mathrm{PM}_{2.5}$ concentrations, solar radiation, sunshine hours showed statistically significant impact on window-opening probability.

3) Seasonal change also has an obvious influence on window-opening behavior, reflected by various different patterns in window-opening probability in different seasons, even at similar indoor or outdoor air temperatures conditions. In the whole year, the window-opening probability mainly varies with outdoor air temperature.

4) The window state also varies at different time of the day. Occupants tend to maintain the existing state of their windows until they feel uncomfortable. When they feel dissatisfied with the environment, they will change the window state to adjust the indoor comfort environment. In addition, there is the highest window-opening probability at the core working time till the late afternoon. Occupants prefer to open their windows when they firstly arrived their offices and close the windows when they left their offices at the end of the day.

5) Different people have various personal preferences on using windows. They may prefer different window states even at similar indoor or outdoor air temperature conditions. However, the general trend keeps the same, which is general proportional to indoor and outdoor air temperatures.

Owing to the inherent limitations on monitored samples, influences from some other potential factors cannot been covered in this study, such as occupncy pattern, gender and age of users, orientation of the window. Moreover, windows monitored in this study are equipped with internal and external blinds, and occupants' window use may 
potentially be influenced by the use of blinds, view from the window, and daylight illuminance falling on the window and direct sunlight penetrating through the window [35]. In addition, window opening area has not been taken into account in this study, due to the limitation of measurement method. Further studies should be done to strengthen the influences from the above factors with a higher number of samples.

\section{Acknowledgements}

The work was supported by 'the 13th Five-Year' National Science and Technology Major Project of China (Grant No. 2017YFC0702202), Beijing Natural Science Foundation (3172041) and the aegis of Engineering Research Center of Digital Community, Ministry of Education and Beijing Laboratory For Urban Mass Transit and National Natural Science Foundation of China (Nos. 51578011 and 51590912).

\section{References}

[1] Andersen R, Toftum J, Andersen K, Olesen B. Survey of occupant behaviour and control of indoor environment in Danish dwellings. Energy and Buildings 2009;41:11-16.

[2] Haldi F, Robinson D. On the behaviour and adaptation of office occupants. Building and Environment 2008;43:2163-77.

[3] M. Luo, B. Cao, X. Zhou, M. Li, J. Zhang, Q. Ouyang, Y. Zhu, Can personal control influence human thermal comfort? A field study in residential buildings in China 
in winter. Energy and Buildings, 72 (0) (2014) 411-418.

[4] Yik F W H, Lun Y F. Energy saving by utilizing natural ventilation in public housing in Hong Kong.[J]. Indoor \& Built Environment, 2010, 19(1):73-87.

[5] Rackes A, Waring M S. Modeling impacts of dynamic ventilation strategies on indoor air quality of offices in six US cities[J]. Building \& Environment, 2013, 60(60):243-253.

[6] Ben-David T, Waring M S. Impact of natural versus mechanical ventilation on simulated indoor air quality and energy consumption in offices in fourteen U.S. cities[J]. Building \& Environment, 2016, 104:320-336.

[7] Ziling Xie, linzhu Sun, Fang Yang. Analysis of the correlation between the energy saving ratio and its occupant window behavior for the natural ventilation residence[J]. Building Energy \& Environmen, 2013,32(1):20-23.

[8] S. Wei, R. Buswell, D. Loveday, A comparison of alternative occupant classification approaches for the modelling of window opening behaviour in office buildings. In: NCEUB (Ed.) 8th Windsor Conference: Counting the Cost of Comfort in a changing world, Cumberland Lodge, Windsor, UK, 2014.

[9] S. Wei, R. Buswell, D. Loveday, Factors affecting ‘end-of-day’ window position in a non-air-conditioned office building. Energy and Buildings, 62 (0) (2013) 87-96.

[10] Y. Zhang, P. Barrett, Factors influencing the occupants' window opening behaviour in a naturally ventilated office building. Building and Environment, 50 (2012) 125134. 
[11]F.J. Nicol, Characterising occupant behaviour in buildings: towards a stochastic model of occupant use of windows, lights, blinds, heaters and fans in: Building Simulation Conference 2001, Rio de Janeiro, Brazil, 2001.

[12]H.B. Rijal, P. Tuohy, M.A. Humphreys, F.J. Nicol, A. Samuel, J.A. Clarke, Using results from field surveys to predict the effect of open windows on thermal comfort and energy use in buildings. Energy and Buildings, 39(7) (7) (2007) 823-836.

[13]H.B. Rijal, P. Tuohy, M.A. Humphreys, F.J. Nicol, A. Samuel, I.A. Raja, J.A. Clarke, Development of adaptive algorithms for the operation of windows, fans, and doors to predict thermal comfort and energy use in Pakistani buildings. ASHRAE Transactions, 114(2) (2) (2008) 555-573.

[14]G.Y. Yun, H. Kim, J.T. Kim, Thermal and non-thermal stimuli for the use of windows in offices. Indoor and Built Environment, 21 (2012) 109-121.

[15] G.Y. Yun, K. Steemers, Time-dependent occupant behaviour models of window control in summer. Building and Environment, 43(9) (9) (2008) 1471-1482.

[16] G.Y. Yun, K. Steemers, Night-time naturally ventilated offices: Statistical simulations of window-use patterns from field monitoring. Solar Energy, 84(7) (7) (2010) 1216-1231.

[17]F. Haldi, D. Robinson, A comparison of alternative approaches for the modelling of window opening and closing behaviour. In: Windsor 2008 Conference: Air Conditioning and the Low Carbon Cooling Challenge, NCEUB, Cumberland Lodge, Windsor, UK, 2008. 
[18]F. Haldi, D. Robinson, A comprehensive stochastic model of window usage: theory and validation. In: Building Simulation Conference 2009, Glasgow, Scotland, 2009, pp. 545-552.

[19]F. Haldi, D. Robinson, Interactions with window openings by office occupants. Building and Environment, 44 (12) (2009) 2378-2395.

[20]R. Andersen, V. Fabi, J. Toftum, S.P. Corgnati, B.W. Olesen, Window opening behaviour modelled from measurements in Danish dwellings. Building and Environment, 69 (0) (2013) 101-113.

[21] S. Herkel, U. Knapp, J. Pfafferott, A preliminary model of user behaviour regarding the manual control of windows in office buildings. In: Building Simulation Conference 2005, Montreal, Canada, 2005.

[22] S. Herkel, U. Knapp, J. Pfafferott, Towards a model of user behaviour regarding the manual control of windows in office buildings. Building and Environment, 43(4) (4) (2008) 588-600.

[23] V. Fabi, R. Andersen, S. Corgnati, B. Olesen, A methodology for modelling energyrelated human behaviour: Application to window opening behaviour in residential buildings. Build. Simul., 6 (4) (2013) 415-427.

[24]Li N, Li J, Fan R, etc. Probability of occupant operation of windows during transition seasons in office buildings[J]. Renewable Energy, 2015, 73:84-91.

[25] G.Y. Yun, K. Steemers, N. Baker, Natural ventilation in practice: linking facade design, thermal performance, occupant percepion and control. Build Res Inf 
2008;36(6):608e 24 .

[26]Rune Vinther Andersen, Jørn Toftum, Klaus Kaae Andersen, etc. Survey of occupant behaviour and control of indoor environment in Danish dwellings[J]. Energy and Buildings, 2009, 41(1):11-16.

[27] Wei S, Jones R, Wilde P D. Driving factors for occupant-controlled space heating in residential buildings[J]. Energy \& Buildings, 2014, 70(70):36-44.

[28] Yun G Y, Tuohy P, Steemers K. Thermal performance of a naturally ventilated building using a combined algorithm of probabilistic occupant behaviour and deterministic heat and mass balance models[J]. Energy \& Buildings, 2009, 41(5):489-499.

[29] Weihuang Chen. Study on the summer thermal comfort and the occupant window behavior for the hot summer and cold winter region[D]. Hunan: Master's thesis, HVAC, Hunan University, 2009.

[30] Jian Zhang. Research on the impact of building orientation and height on window ventilation of office users[J]. Huazhong Architecture,2011,(08):50-53.

[31] Watterson TL, Sorensen J, Martin R, Coulombe RA Jr.Effects of PM2.5 collected from Cache Valley Utah on genes associated with the inflammatory response in human lung cells[J]. J Toxicol Environ Health A, 2007,70(20):1731-1744.

[32]Hosmer, D.W. \& Lemesbow, S. 2000. Applied logistic regression (2nd Edition), New York: John Wiley \& Sons, Inc.

[33] O'Brien W, Gunay H B. The contextual factors contributing to occupants' adaptive 
comfort behaviors in offices - A review and proposed modeling framework[J]. Building \& Environment, 2014, 77:77-87.

[34] Karjalainen, Sami. Should we design buildings that are less sensitive to occupant behaviour? A simulation study of effects of behaviour and design on office energy consumption. Energy Efficiency (2016): 1-14.

[35]Zhang Y, Barrett P. Factors influencing the occupants' window opening behaviour in a naturally ventilated office building[J]. Building \& Environment, 2012, 50(50):125-134 